\title{
Management of Hepatitis C Before and After Liver Transplantation in the Era of Rapidly Evolving Therapeutic Advances
}

\author{
Chalermrat Bunchorntavakul ${ }^{1}$ and K. Rajender Reddy ${ }^{2}$ \\ ${ }^{1}$ Division of Gastroenterology and Hepatology, Department of Medicine, Rajavithi Hospital, College of Medicine, Rangsit \\ University, Bangkok, Thailand; ${ }^{2}$ Hospital of the University of Pennsylvania, University of Pennsylvania, Philadelphia, PA, USA
}

\begin{abstract}
Management of hepatitis C (HCV) in liver transplantation (LT) population presents unique challenges. Suboptimal graft survival in $\mathrm{HCV}+\mathrm{LT}$ recipients is attributable to universal $\mathrm{HCV}$ recurrence following LT. Although eradication of HCV prior to LT is ideal for the prevention of HCV recurrence it is often limited by adverse events, particularly in patients with advanced cirrhosis. Antiviral therapy in LT candidates needs careful monitoring, and prophylaxis with HCV antibodies is ineffective. Early antiviral therapy after LT has been investigated, but no clear benefit has been demonstrated. Protocol liver biopsy is generally recommended in HCV+ LT recipients, and antiviral therapy can be considered in those with severe/ progressive HCV recurrence. Sustained virological response (SVR) can be achieved in approximately $30 \%$ of LT recipients with pegylated interferon/ribavirin (PEG-IFN/RBV) with survival benefit, but adverse effects are common. Favorable patient characteristics for response to therapy include non-1 genotype, previously untreated, low baseline HCV-RNA, and donor IL28B genotype CC. Direct acting antiviral (DAA)based triple therapy is associated with higher rates of SVR, but with similar or slightly higher rates of side effects, and immunosuppressive regimens need to be closely monitored and adjusted during the treatment period. Notably, the safety and efficacy of HCV treatment are very likely to improve with newer generation DAA. The benefit of immunosuppressive strategy on the natural history HCV recurrence has not been well elucidated. Based upon available evidence, cyclosporine A (CSA), mycophenolate mofetil (MMF), and sirolimus appear
\end{abstract}

Keywords: Hepatitis C; Liver transplantation; Prevention; Treatment; Interferon; Protease inhibitors; Immunosuppression.

Abbreviations: ACR, acute cellular rejection; AIH, autoimmune hepatitis; ATG, anti-thymocyte globulin; AUC, area under the curve; BOC, boceprevir; $C R$, chronic rejection; CSA, cyclosporine $A$; CTP, Child-Turcotte-Pugh; DAA, direct acting antivirals; EVR, early virological response; $\mathrm{HCC}$, hepatocellular carcinoma; HCIG, hepatitis C immunoglobulins; HCV, hepatitis C virus; IMPDH, inosine monophosphate dehydrogenase; LADR, low accelerating dosage regimen; LT, liver transplantation; MELD, Model of End-stage Liver Disease; MMF, mycophenolate mofetil; mTOR, mammalian target of rapamycin; PEG-IFN, pegylated interferon; RBV, ribavirin; RT, retransplantation; RVR, rapid virological response; SVR, sustained virological response; T1/2, terminal elimination half-life; TAC, tacrolimus; TVR, telaprevir; UNOS/SRTR, United Network of Organ Sharing/ Scientific Registry of Transplant Recipients.

Received: 01 January 2014; Revised: 13 February 2014; Accepted: 20 February 2014

DOI of original article: 10.14218/JCTH.2014.00002.

Correspondence to: K. Rajender Reddy, 2 Dulles, 3400 Spruce Street, Hospital of the University of Pennsylvania, Philadelphia, PA 19104, USA. Tel: +1-215-6624311, E-mail: rajender.reddy@uphs.upenn.edu to have a neutral or small beneficial impact on HCV recurrence. Donor interleukin 28 B (IL28B) polymorphisms appear to impact the course and treatment outcomes in recurrent HCV. Retransplantation should be considered for patients with reasonable survival probability.

(C) 2014 The Second Affiliated Hospital of Chongqing Medical University. Published by XIA \& HE Publishing Ltd. All rights reserved.

\section{Introduction}

Chronic hepatitis $\mathrm{C}$ virus ( $\mathrm{HCV}$ ) infection is the leading cause of cirrhosis and hepatocellular carcinoma (HCC) worldwide. As a consequence, it is the most common indication for liver transplantation (LT) in the United States, Japan, and many countries in Europe. Despite advances in anti-viral therapy, current estimates indicate that the prevalence of HCV and its associated complications will continue to rise over the next two decades. ${ }^{1,2}$ Recurrence of $\mathrm{HCV}$ in the allograft is universal, occurring soon after liver transplantation, and may be associated with accelerated progression to cirrhosis, graft loss, and death. 2,3 Therefore, management of chronic $\mathrm{HCV}$ infection before and after LT is an important component of current and future clinical practice.

Current approaches to the management of HCV patients before and after LT fall into four broad categories based on the time of intervention: (1) treatment of patients with cirrhosis awaiting LT; (2) prophylaxis defined as initiation of therapy at the time of LTand continued post-LT with the goal of preventing recurrent infection; (3) early post-LT (within the first 6 months after LT); and (4) HCV therapy for established disease. ${ }^{4}$

The overall outcome of antiviral therapy in this setting is suboptimal; however, it can be successfully utilized in selected populations with careful monitoring. Unique challenges and issues in the LT population in the context of HCV therapy include the tolerability of pegylated-interferon (PEGIFN) and ribavirin (RBV) and more recently of the direct acting antivirals (DAA), the need to modify immunosuppressive regimens during DAA therapy because of drug-drug interactions, the risk of graft rejection, and the role of genetic polymorphisms on response to therapy. ${ }^{5}$

\section{Natural history of hepatitis C before and after LT}

Approximately $15-20 \%$ of patients with HCV-related cirrhosis evolve to hepatic decompensation and/or develop HCC within 10 years. ${ }^{6}$ If these complications are left untreated, 
Bunchorntavakul C. et al.: Hepatitis C before and after liver transplantation

prognosis is poor and these patients will require LT as a lifesaving procedure. In addition, graft and patient survival are significantly reduced in HCV-positive recipients compared to HCV-negative recipients, a difference mainly accounted for by recurrence of $\mathrm{HCV}$ infection in the graft. ${ }^{7} \mathrm{HCV}$ recurrence is almost universal and its severity depends on several host, viral, donor, and transplant factors (Table 1). ${ }^{2,8-10}$

Following LT, the liver graft is re-infected upon reperfusion, and is accompanied by a rise in HCV viral load that peaks around 3-4 months. Most patients develop features of acute hepatitis between 4 and 12 weeks after LT. ${ }^{4}$ Though serum transaminases and HCV-RNA generally settle down to normal or near normal range, spontaneous viral clearance has not been observed. ${ }^{2-4}$ At the end of the first year, HCV-RNA levels are, on an average, 10-20-fold higher than pre-LT levels. Histological evidence of chronic hepatitis $C$ is encountered in $50-80 \%$ of patients after $6-12$ months. ${ }^{2,3,11}$ The natural course of hepatitis $C$ is accelerated in liver transplant recipients, with more than $40 \%$ progressing to cirrhosis

Table 1. Factors associated with an increased incidence and/or increased severity of recurrence in HCV following liver transplantation

Risk factors for severe HCV recurrence

\section{Pre-transplant factors}

Host factors

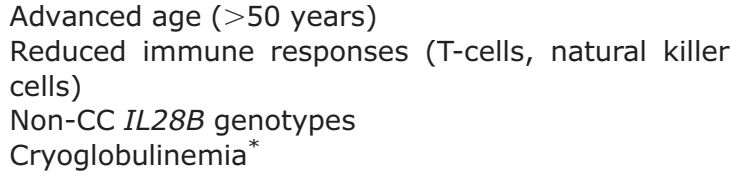

Viral factors

Genotype 1

High HCV-RNA levels

HIV co-infection

\section{Donor factors}

Advanced donor age ( $>35$ years)

Liver steatosis

Non-CC IL28B genotypes

HLA mismatch*

High liver iron concentration*

\section{Transplant factors}

Prolonged cold ischemic time ( $>12$ hours)

Preservative injury

\section{Post-transplant factors}

Early / high HCV-RNA levels

Rejection episode(s)

Corticosteroids: pulse therapy, high accumulation dose, early/ rapid withdrawal

CMV and HHV-6* infection

OKT3, ALG*, ATG*

Post-LT diabetes mellitus*

*Possible risk factor (limited and/or controversial data)

Abbreviations: HCV, hepatitis C virus; LT, liver transplantation; HIV , human immunodeficiency virus; HLA, human leukocyte antigen CMV, cytomegalovirus; HHV, human herpes virus; ALG, anti-lymphocyte globulins; ATG, anti-thymocyte globulins within 10 years and approximately 50\% developing liver failure shortly thereafter (Fig. 1)..$^{2-6,11}$

A subset of patients (2-9\%) may develop post-LT cholestatic hepatitis $\mathrm{C}$, which is characterized by persistent cholestasis of at least 4 weeks in duration, high HCV-RNA, hepatocyte ballooning, rapid progression to graft failure, and, in the absence of biliary and hepatic artery complications, sepsis and drug-related cholestasis. ${ }^{12}$ This complication is usually resistant to antiviral therapy and leads to death in more than $50 \%$ of patients within the first year after $\mathrm{LT}_{i}$ retransplantation (RT) is associated with poor outcomes. ${ }^{2,12,13}$

Due to the lack of sensitivity and specificity of serum transaminases in determining the severity of recurrent hepatitis, HCV recipients ideally should undergo protocol liver biopsies in order to determine disease severity and prognosis starting from around 6-12 months and then annually following LT. Early post-LT histology has been consistently predictive of subsequent fibrosis progression. ${ }^{2,3}$ Several preliminary studies have suggested that non-invasive markers, especially transient elastography, correlated well with the degree of graft fibrosis and outcomes in HCV+ LT recipients. ${ }^{14-17}$ A recent study of $144 \mathrm{HCV}$-infected and 48 non-HCV-infected LT recipients reported that the liver stiffness measurement at one year after $L T$ is a valuable predictor of liver-related outcomes in recurrent HCV (cumulative probabilities of liver decompensation five years after LT were $8 \%$ for patients with liver stiffness measurement $<8.7$ kilopascals versus $47 \%$ for patients with $\geqslant 8.7$ kilopascals; $\mathrm{p}<0.001$ ) and can be used in clinical practice to identify the best candidates for antiviral therapy. ${ }^{18}$ This tool can be very useful as an alternative or complementary test to invasive protocol biopsies for monitoring post-LT recurrent hepatitis $\mathrm{C}$ and to identify the best candidates for antiviral therapy. However, studies with a longer follow-up period and larger sample size are needed to confirm these preliminary results. Nevertheless, the decision to intervene therapeutically has varied across centers and is mostly tailored to the severity of liver disease, although a strategy to treat all with any degree of recurrent hepatitis has also been pursued.

\section{Management of hepatitis C before and after LT}

The goal of HCV management in the setting of $L T$ is to prevent or cure recurrent HCV disease. Current approaches can be divided into four broad categories according to the time of intervention (Fig. 2). ${ }^{4}$

\section{Management of hepatitis C in LT candidates}

Management of patients with HCV cirrhosis awaiting LT aims to attain sustained virological response (SVR), slow liver disease progression, and prevention of liver graft infection. Successful viral eradication in patients with cirrhosis independently reduces the likelihood of clinical decompensation and improves survival, which may then facilitate, delay, or, in a small proportion of patients, avoid LT. ${ }^{4,19}$ Furthermore, high pre-LT HCV-RNA levels are strongly associated with poor graft and patient survival and are driven by HCV recurrence. Taken together, these findings support the necessity to treat HCV prior to LT. Notably, in patients who achieved SVR prior to LT, the incidence of HCV recurrence is very low $(0-20 \%) .^{2-4,9,19}$

Several uncontrolled and controlled prospective studies have evaluated the efficacy and safety of antiviral therapy 

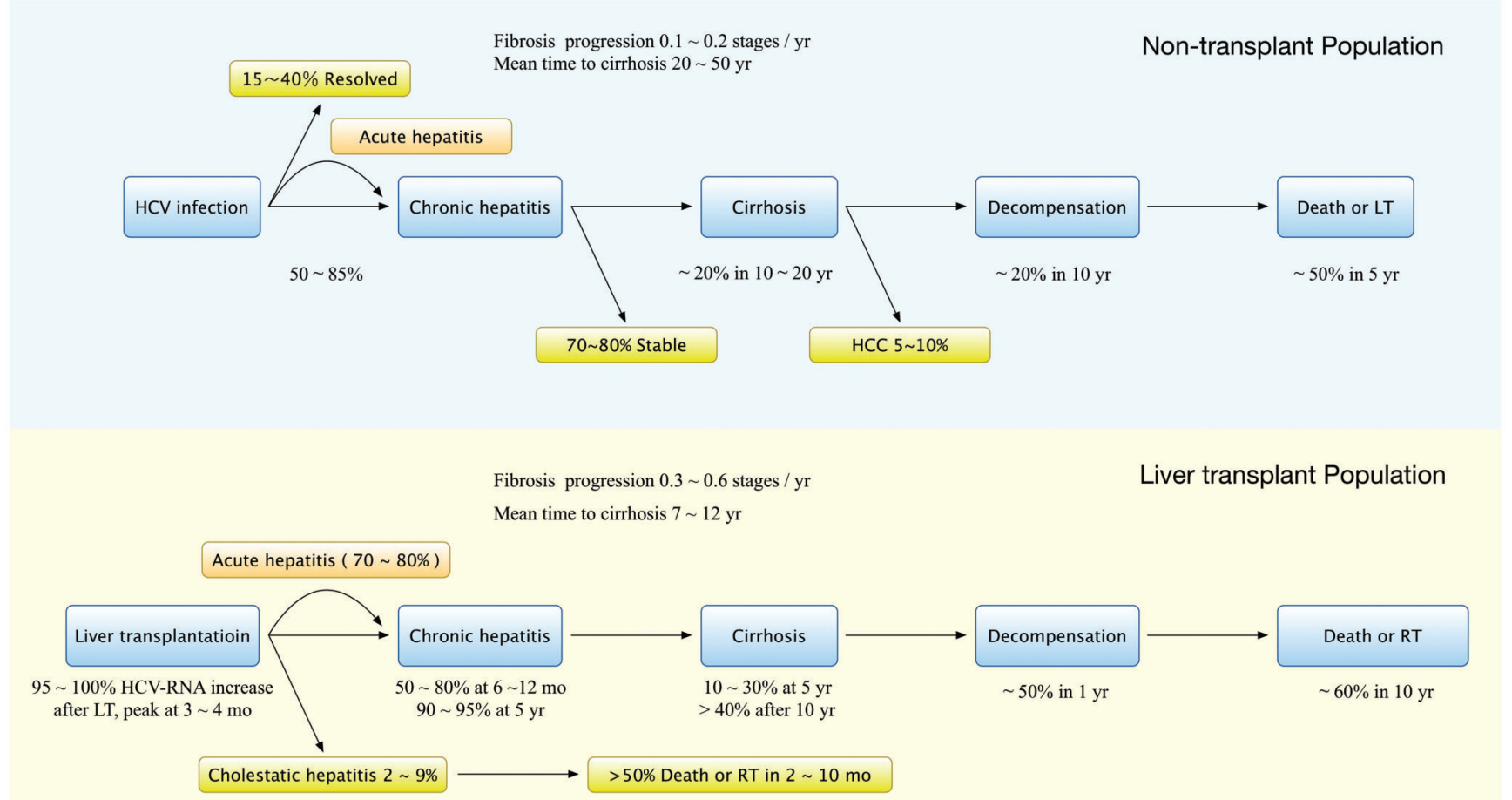

Fig. 1. Natural history of HCV in non-transplant and liver transplant populations. Abbreviations: HCV, hepatitis C virus; LT, liver transplantation; RT, retransplantation

with IFN or PEG-IFN and RBV in LT candidates. SVR was achieved in $7-30 \%$ of patients with HCV genotype 1 , whereas $44-57 \%$ of patients with genotype $2 / 3$ achieved SVR. ${ }^{4,20}$ Predictors of SVR were genotypes $2 / 3$, early virological response (EVR), low HCV-RNA, adherence to full dose(s)/ duration of treatment, and IL28B genotype CC. ${ }^{21}$ Everson et al. treated 124 patients with decompensated cirrhosis by a low accelerating dosage regimen (LADR) using either IFN $1.5 \mathrm{MU}$ thrice weekly or PEG-IFN alfa-2b $0.5 \mu \mathrm{g} / \mathrm{kg}$ once weekly plus RBV $600 \mathrm{mg} / \mathrm{day}$, and gradually increased the doses every two weeks until they reached the maximum tolerated or target standard doses. SVR was $13 \%$ in patients with genotype 1 and $50 \%$ in those patients with non-1 genotypes. Adverse events were frequent in patients with cirrhosis awaiting LT, which led to dose reduction in $40-70 \%$ and treatment discontinuation in $13-40 \%$ of patients. ${ }^{4}$ The incidence of infections, particularly spontaneous bacterial peritonitis in patients not receiving quinolone prophylaxis, was significantly higher in patients on antiviral therapy than in those who did not receive therapy. ${ }^{22}$ Treatment-induced cytopenias have commonly been managed by dose reduction and hematopoietic growth factors.

Currently, four direct-acting antivirals, including boceprevir (BOC), telaprevir (TVR), simeprevir, and sofosbuvir, have been approved for the treatment of HCV genotype 1 as part of a three-drug combination with PEG-IFN/RBV. These DAAbased triple therapies have been shown to improve virological outcomes in HCV genotype 1 patients, with an SVR of up to $65-86 \%$ in treatment naïve patients and $29-83 \%$ in previous relapsers/non-responders. ${ }^{23-28}$ However, the data on safety and efficacy of DAA-based triple therapy in cirrhosis and LT candidates are limited. Adverse effects of treatment, particularly anemia, are more frequently observed with BOC and TVR therapies. ${ }^{24-27}$ Though treatment-induced anemia is generally manageable by dose reduction and erythropoiesis-stimulating agent, severe anemia could develop more frequently and lead to treatment discontinuation in more vulnerable cirrhotic patients. Cure rates in patients with advanced fibrosis were significantly lower than in patients with mild to moderate fibrosis, although results were still encouraging. ${ }^{20}$ However, there is no data available regarding the efficacy of BOC and TVR in patients with decompensated cirrhosis, where safety is the major concern. ${ }^{20}$ A French Cohort (CUPIC Study Group) of compensated HCV cirrhosis treated with $B O C$ or TVR $(\mathrm{N}=674)$ reported a high incidence of serious adverse events $(40 \%)$, severe complications, death $(6 \%)$, and a difficult management of anemia $(63 \%) .{ }^{29}$ Death or severe complications were related to platelets count $\leqslant 100,000 / \mathrm{mm}^{3}$ (OR 3.11, 95\% CI; $1.30-$ 7.41 ) and albumin $<3.5 \mathrm{~g} / \mathrm{L}$ (OR 6.33, 95\%CI; 2.66-15.07), with a risk of $44 \%$ in patients with both. ${ }^{29}$

In the foreseeable future, IFN-free DAA regimens are likely to become available and expected to have high efficacy with low side effects, ${ }^{30}$ which are perhaps worthy options for managing HCV in LT candidates. There was a recent case report using all-oral DAA (initially TVR and RBV and then BOC and RBV) in the pre-transplant period, to prevent reinfection of the liver graft after LT for advanced HCV-related cirrhosis. ${ }^{31}$ A preliminarily report of the multi-center, open-label Phase 2 Study ( $\mathrm{N}=61$ ) evaluating sofosbuvir plus RBV (taken 
Bunchorntavakul C. et al.: Hepatitis C before and after liver transplantation

\begin{tabular}{|c|c|c|}
\hline & Timing & Available Strategies and Outcomes \\
\hline 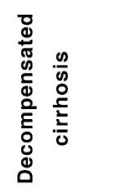 & Prior to LT & $\begin{array}{l}\text {-PEG-IFN+RBV (LADR ?) - SVR } 7 \sim 30 \% \text { in G1; 44 57\% in G2/3 } \\
\text {-DAA-based triple therapy-high side effects (not recommended) } \\
\text {-Rx of portal HT and HCC surveillance } \\
\text {-INF-free DAA regimens are preferred? }\end{array}$ \\
\hline & Around the time of LT & $\begin{array}{l}\cdot \mathrm{HCIG}, \mathrm{HCV}-\mathrm{E} 2 \text { monoclonal antibody - not effective } \\
\text { •High-dose IV silibinin? } \\
\text {-Organ from IL28B C/C donor? }\end{array}$ \\
\hline 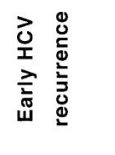 & $\begin{array}{l}\text { Early after LT } \\
\text { (within } 6 \mathrm{mo} \text { ) }\end{array}$ & $\begin{array}{l}\text {-Preemptive/early PEG-IFN+RBV - SVR 13 35\% (not recommended) } \\
\text {-Avoid OKT3 and pulse steroid, if possible } \\
\text {-IMS with antiviral } \pm \text { antifibrotic properties: CSA, MMF, mTOR? }\end{array}$ \\
\hline 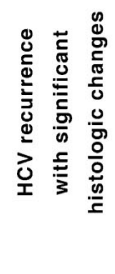 & $\begin{array}{l}\text { Established severe/ } \\
\text { progressive } \\
\text { recurrent HCV disease }\end{array}$ & $\begin{array}{l}\text {-Protocol biopsy or LSM-to determine severity and prognosis } \\
\text {-PEG-IFN+RBV - SVR } 24 \sim 40 \% \\
\text {-DAA-based therapy with monitoring of IMS levels - SVR }>50 \% \\
\text {-Newer generation of DAA (IFN-free regimens?) are preferred } \\
\text {-Hematopoietic growth factor? } \\
\text {-Switching to CSA-based regimen before antiviral treatment? }\end{array}$ \\
\hline 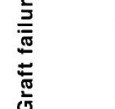 & $\begin{array}{l}\text { Graft failure form } \\
\text { HCV recurrence }\end{array}$ & $\begin{array}{l}\text {-Retransplantation -reduced graft survival compare to } 1^{\text {st }} \text { graft } \\
\text { (consider in patients with reasonbale survival probability) }\end{array}$ \\
\hline
\end{tabular}

? - Limited or controversial data

Fig. 2. Summary of available HCV management options before and after liver transplantation. Abbreviations: HCV, hepatitis $C$ virus; $L T$, liver transplantation; PEG-IFN, pegylated interferon; RBV, ribavirin, LADR, low accelerated dose regimen; SVR, sustained virologic response; G, genotype; HCC, hepatocellular carcinoma; IFN, interferon; DAA, direct acting antivirals; HCIG, Hepatitis C immune globulin; IV, intravenous; IL, interleukin; IMS, immunosuppressive drugs; CSA, cyclosporine A; MMF, mycophenolate mofetil; mTOR, the mammalian target of rapamycin inhibitors; LSM, liver stiffness measurement

for 24-48 weeks before LT) to prevent HCV recurrence following LT has shown promising results. ${ }^{32}$ Participants had well-compensated liver disease (the median MELD score was 8) and were listed for LT due to HCC; $73 \%$ had HCV genotype $1,13 \%$ had genotype $2,12 \%$ had genotype 3 , and $2 \%$ had genotype 4 . More than $90 \%$ of patients who received treatment had undetectable HCV-RNA at the time of LT. Among those with undetectable HCV at LT, 64\% maintained viral suppression at 12 weeks post-LT. ${ }^{32}$ Sofosbuvir/RBV was generally safe and well-tolerated with 11 serious adverse events reported during the study (none of which were considered related to sofosbuvir). ${ }^{32}$

Taken together, antiviral therapy with PEG-IFN/RBV in the setting of HCV cirrhosis should be used in properly selected populations with careful monitoring by those experienced in hepatitis $C$ treatment. Given the high rate of serious adverse events among patients with more advanced liver disease, treatment is contraindicated when the Child-Turcotte-Pugh (CTP) score is $>11$ or the Model of End-stage Liver Disease (MELD) score is $>25$, whereas treatment should be considered if CTP $\leqslant 7$ or MELD $\leqslant 18 .^{3,33}$ DAA-based triple therapy should not be used in LT candidates outside of carefully designed clinical trials, and IFN-free regimens are required for this vulnerable population.

\section{Prophylactic therapy}

Immune globulin containing virus-specific antibodies have been shown to be effective in the treatment of several viral diseases, as well as in the prevention of recurrent hepatitis $B$ after LT. $^{4}$ In animal studies, immune globulin enriched in antibody to $\mathrm{HCV}$ ( $\mathrm{HCIG}$ ) was able to neutralize infectious inoculates and delay or prevent HCV infection. ${ }^{34}$ Therefore, HCIG might have a role in preventing recurrent HCV after LT.

Unfortunately, clinical studies of HCV antibody therapy using polyclonal $\mathrm{HCIG}^{34}$ and anti-E2 monoclonal antibody ${ }^{35}$ have not proven to be effective. In a Phase II study of monoclonal antibody $\mathrm{HCV}-\mathrm{Ab}^{\mathrm{XTL}} 68,24$ patients were randomized to receive 2-4 infusions of either placebo, low-dose HCV-Ab ${ }^{\mathrm{XTL}} 68$, or high-dose HCV-Ab ${ }^{\mathrm{XTL}} 68$ during the first 24 hours after LT, followed by daily infusions for six days, weekly infusions for three weeks, and either two or four weekly infusions for eight weeks. Significant HCV-RNA reduction was achieved in a dose-related manner, although all patients became viremic after $\mathrm{LT}^{35}$ Preliminary data suggested that high-dose intravenous silibinin given immediately after LT may prevent HCV recurrence. ${ }^{36}$ However, this approach needs to be further evaluated. Recently, a Cochrane Systematic Review (included 10 trials; $441 \mathrm{HCV}+$ LT recipients) reported that there 
were no significant differences in mortality rates, worsening of fibrosis, HCV recurrence, serious adverse events, or graft rejection between intervention and control groups. ${ }^{37}$ Therefore, at present, there is no demonstrated role for antiviral or HCV antibody therapy in the management of HCV patients undergoing LT.

\section{Early post-transplant or preemptive antiviral therapy}

Preemptive antiviral strategy typically initiates antiviral treatment within the first two months after LT. The rationale for this approach is supported by the experience from the treatment of acute hepatitis $C$ in the non-transplant population, where SVR rates are very high when therapy is initiated early. ${ }^{4}$ Therefore, intervening at an early time point with relatively low HCV-RNA levels in the absence of significant histological changes in the graft might lead to better treatment outcomes in recurrence HCV infection. The majority of clinical studies of preemptive therapy in LT recipients was uncontrolled and used a combination of conventional IFN/RBV. ${ }^{4,20}$ Overall results have been somewhat disappointing; rates of SVR varied between $5-33 \%$ in genotype 1 and $14-100 \%$ in genotype 2/ 3 patients. ${ }^{4,20}$ More recent controlled studies have evaluated the efficacy of 48-week therapy in the early post-LT (mean 34 months) with standard dose ${ }^{38}$ and escalating dose regimen of PEG-IFN/RBV; ${ }^{39}$ SVR was achieved in $13-35 \%$ of patients. ${ }^{4,38,39}$ Preemptive treatment was associated with high rates of treatment dose reduction (28-85\%) and discontinuation $(0-37 \%)$. Furthermore, transplant-related factors, such as high levels of immunosuppression, can decrease the likelihood of HCV eradication, and post-surgical and infectious complications may preclude patients as treatment candidates.

A recent multi-center, randomized controlled trial of 115 patients comparing early treatment (10-26 weeks after LT) and treatment of established histologic HCV recurrence (Phoenix trial) with PEG-IFN/RBV showed similar SVR rates in both treatment groups ( $22 \%$ vs. $21 \%$, respectively). Survival, adverse events, dose reduction, and acute cellular rejection (ACR) rates were no different between the groups. ${ }^{40}$ Thus it appears that there is no established role of early postLT HCV therapy.

\section{Treatment of established $\mathrm{HCV}$ recurrence}

Antiviral therapy is considered in LT recipients who develop significant or progressive recurrent HCV disease, as defined by moderate to severe necroinflammatory activity (grade 34) and/or significant fibrosis (stage 2-4) on histologic evaluation. ${ }^{33}$ Treatment of recurrent HCV in LT recipients, particularly with successful viral eradication, is associated with a reduced risk of graft failure. ${ }^{41}$ Five-year survival has been reported to be significantly greater in patients with SVR than non-responders (93\% vs. $69 \%$, respectively)..$^{42}$

The majority of data on efficacy and safety of treatment come from retrospective and uncontrolled studies, and few randomized controlled studies have been performed to date. ${ }^{43-45}$ The majority of patients included were genotype 1 , and most studies employed a reduced dose of RBV (400$800 \mathrm{mg} /$ day) and/or PEG-IFN, as well as hematopoietic growth factors. The pooled estimate of SVR from prospective studies was $24-40 \% .{ }^{4}$ Biochemical and histological responses were observed in approximately $50 \%$ of treated patients. Remarkably, virologic relapse occurred in a substantial proportion (21-43\%) of LT recipients who achieved end-oftreatment response. ${ }^{19,43,44}$ Two-thirds of patients required dose reductions of either IFN or RBV and one-fourth discontinued treatment early. ${ }^{3}$ Baseline factors associated with SVR included non-1 genotype, previously untreated, low baseline HCV-RNA, adherence to therapy, and donor IL28B genotype CC. ${ }^{8,10,21,43,45-47}$ On-treatment predictors matched those in the non-transplant setting; achievement of rapid virological response (RVR) was a good predictor of SVR, and failure to achieve EVR was highly predictive for non-SVR. ${ }^{43,48}$

The use of DAA with PEG-IFN and RBV in the management of post-transplant recurrent HCV is challenging. As in noncirrhotic cases, one could speculate that DAA might also improve SVR rates in HCV patients in the post-LT state. However, caution must be exercised due to limited data on efficacy and safety of DAA in this population.

Another challenge in utilizing DAA in LT recipients is the potential drug interaction with immunosuppressive agents. TVR and BOC, as well as many other DAAs, are substrates and possibly weak inhibitors of cytochrome P450 3A4.4,49 Lessons from HIV patients have demonstrated that protease inhibitors, particularly when boosted by ritonavir, can lead to a profound increase in serum levels of calcineurin inhibitors and sirolimus. ${ }^{50}$ A recent pharmacokinetic study demonstrated that co-administration of telaprevir significantly increased the dose-normalized exposure (AUC) and terminal elimination half-life $\left(T^{1 / 2}\right)$ of both cyclosporine (CSA) (AUC increased 4.6-fold; mean $T^{1 / 2}$ increased from 12 to 42 hours) and tacrolimus (TAC) (AUC increased $\sim 70$-fold; mean $T^{1 / 2}$ increased from 40.7 to 196 hours). ${ }^{51}$ Subsequent clinical studies have demonstrated that BOC and TVR could be administered in LT recipients with close monitoring of immunosuppressive drug levels. ${ }^{52-57}$ BOC induced a reduction in the estimated oral clearance of CSA of $50 \%$, of TAC of up to $80 \%$, and of everolimus of $50 \% .^{53,56}$ With TVR, the doses of CSA, sirolimus, and TAC were reduced by $2.5,7$, and 22 -fold, respectively. ${ }^{55} \mathrm{~A}$ recent multi-center cohort study included $37 \mathrm{HCV}+\mathrm{LT}$ recipients treated with BOC $(n=18)$ or TVR $(n=19)$ and noted ETR rates of $72 \%(13 / 18)$ and $40 \%$ $(4 / 10)$, and SVR12 rates of $20 \%(1 / 5)$ and $71 \%(5 / 7)$ with TVR and BOC, respectively. The doses of CSA (1.8 \pm 1.1 -fold

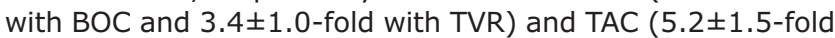
with BOC and 23.8 \pm 18.2 -fold with TVR) were reduced in all patients during the treatment. The most common adverse effect was anemia (92\%). Treatment was discontinued in 16 patients $(43 \%)$ ( 11 due to treatment failure and 5 due to adverse events). Infections occurred in 10 patients (27\%), with three fatal outcomes (8\%). Another smaller series reported a SVR rate of $56 \%$ (5/9) with TVR-based triple therapy for LT recipients with recurrent HCV (most of them were previously treated with PEG-IFN/RBV). ${ }^{58}$

There is limited data on the interaction between DAA and mammalian target of rapamycin (mTOR) inhibitors. Recognizing that sirolimus carries a black box warning for use in $\mathrm{LT}^{59}$ it may be sensible to avoid this agent altogether in patients receiving TVR or BOC. ${ }^{52}$ Consideration might be given to everolimus use in place of sirolimus if an mTOR inhibitor is indicated. ${ }^{52}$ The shorter half-life of everolimus may make management of drug-drug interactions easier than sirolimus. $^{52}$

Newer generations of DAA are associated with higher potency, more convenient dosing, and less drug-drug interactions, characteristics that are necessary and ideal for use in LT recipients. ${ }^{49}$ Simeprevir and faldeprevir are mild-moderate 
Bunchorntavakul C. et al.: Hepatitis C before and after liver transplantation

CYP3A4 and OATP1B1 inhibitors, which are likely to have potential but mild drug-drug interactions with calcineurin inhibitors and other OATP1B1 substrates. ${ }^{49}$ Therefore, a small change in calcineurin inhibitor level, as well as unconjugated hyperbilirubinemia, may be expected. ${ }^{49}$ Daclatasvir is metabolized by hepatic CYP3A without clinical evidence of CYP3A inhibition or induction, ${ }^{49}$ and sofosbuvir is excreted by the kidney. Although these two protease inhibitors are not expected to lead to clinically significant drug-drug interactions in LT recipients, confirmatory studies are needed. ${ }^{49}$ Of importance are the recent preliminary results of a multi-center, open-label Phase 2 Study $(\mathrm{N}=40)$ evaluating 24-week sofosbuvir plus RBV for treatment of established HCV recurrence after LT found at week four and at the end of treatment that all participants had undetectable HCV-RNA. ${ }^{60}$ Four weeks after completing treatment, $77 \%$ still had sustained viral suppression (SVR4). No baseline factors were found that predicted which patients would relapse. ${ }^{60}$ While these response rates are promising, it is still early to estimate the rate of SVR as relapse could occur four weeks after cessation of therapy. Serious adverse events were reported in $15 \%$ of patients ( $5 \%$ led to treatment discontinuation), and no interactions were reported between sofosbuvir and any immunosuppressive agents. ${ }^{60}$

Taken together, DDA-based therapy is feasible for LT recipients with severe $\mathrm{HCV}$ recurrence. ${ }^{54,57,58}$ Higher rates of SVR (more than $50 \%$ ) can be expected with BOC- and TVRbased therapy, but close monitoring for side effects and immunosuppressive drug levels are warranted. The use of newer protease inhibitors, such as simeprevir, faldeprevir, daclatasvir, and sofosbuvir, will likely be associated with improved SVR rates in LT recipients as well as fewer drug interactions and side effects. However, optimization of agents and duration of therapy will require further study, and it is likely that IFN-free regimens will be associated with a better safety profile in this population. Recently, cases of severe recurrent cholestatic HCV following LT that were successfully managed by daclastasvir plus PEG-IFN/RBV for 24 weeks ${ }^{61}$ and daclastavir plus sofosbuvir (without IFN) for 24 weeks ${ }^{62}$ have been reported. In both, the treatment regimens were well-tolerated, and calcineurin inhibitors trough levels reached the targeted therapeutic range during and after treatment. ${ }^{61,62}$ Based on available data, the interactions and dosing strategies of currently-approved concomitant protease inhibitor and immunosuppressive agents during HCV therapy are summarized in Table 2.

\section{Special aspects of HCV treatment after LT}

\section{Rejection and autoimmune complications}

$\mathrm{HCV}$ infection itself is associated with a variety of autoimmune phenomena. ${ }^{63}$ Due to the potent immunomodulatory effects of IFN, the risk of graft rejection and other immune complications remain a concern. Additionally, it has been suggested that the improvement in hepatic microsomal function during antiviral therapy may lead to a decrease in serum levels of immunosuppressive agents, which in turn may place patients at a higher risk for ACR. ${ }^{64}$ The reported incidence of ACR following IFN-based therapy in HCV-positive LT recipients ranges from $0-25 \% .{ }^{4}$ Among controlled studies, the occurrence and severity of ACR was not significantly different from that of untreated HCV-positive LT recipients. ${ }^{64}$ A typical manifestation of ACR during IFN-based therapy is a secondary increase in serum transaminases after an initial improvement with treatment and concomitant low or negative serum HCV-RNA. ${ }^{64}$ Nevertheless, this is neither specific nor sensitive, and the accurate diagnosis of ACR requires prompt liver biopsy. Mild forms of ACR can be managed by augmenting baseline immunosuppression, while moderate/ severe form of ACR may require high-dose intravenous corticosteroids. The question of whether or not antiviral therapy should be discontinued at the onset of ACR, particularly in those responding to therapy, remains unclear. Intuitively, it appears that a safe strategy would be to discontinue HCV therapy, unless ACR evolved with low trough levels of immunosuppressive agents, and their doses have been augmented. In that case, HCV therapy can be continued or restarted after ACR has been treated.

Chronic rejection (CR) is a rare but serious complication in $L T$ recipients. The incidence of $C R$ in $H C V$-positive $L T$ recipients varies between $4-8 \%$ in the absence of treatment. ${ }^{65}$ Several uncontrolled studies have suggested that CR may be related to IFN-based therapy (incidence range 4$17 \%) .{ }^{64,66} \mathrm{CR}$ is generally detected after one year of therapy and is often observed concurrent with the absence or low

Table 2. Empiric recommended dosing strategies of concomitant protease inhibitors and immunosuppressive agents during HCV therapy [Adapted from Charlton M, Dick T. J Hepatol 2014;60:6-8.)

\begin{tabular}{|c|c|c|c|c|c|}
\hline \multirow[b]{2}{*}{ Drug } & \multirow{2}{*}{$\begin{array}{l}\text { Mechanism of interaction } \\
\text { and exposure effect }\end{array}$} & \multicolumn{4}{|c|}{ Empiric dose changes* } \\
\hline & & $\mathrm{BOC}$ & TVR & SMV & SFV \\
\hline Cyclosporine & Inhibits CYP3A4: $\uparrow$ drug exposure & $\downarrow 50 \%$ & $\downarrow 75 \%$ & No data (small $\downarrow$ ) & Not necessary \\
\hline Tacrolimus & Inhibits CYP3A4: $\uparrow$ drug exposure & $\downarrow 75 \%$ & $\downarrow 90 \%$ & No data (small $\downarrow$ ) & Not necessary \\
\hline Sirolimus & Inhibits CYP3A4: $\uparrow$ drug exposure & \multicolumn{4}{|c|}{$\begin{array}{l}\text { Black box warning for use in liver transplant. } \\
\text { Recommend everolimus, if mTOR inhibitor indicated. }\end{array}$} \\
\hline Everolimus & Inhibits CYP3A4: $\uparrow$ drug exposure & $\downarrow 50 \%$ & Likely $\downarrow 75 \%$ & No data (small $\downarrow$ ) & Not necessary \\
\hline MMF & No published data, no change known & \multicolumn{4}{|c|}{ No empiric dose adjustments necessary } \\
\hline Azathioprine & No published data, no change known & \multicolumn{4}{|c|}{ No empiric dose adjustments necessary } \\
\hline Prednisolone & No published data, no change known & \multicolumn{4}{|c|}{ No empiric dose adjustments necessary } \\
\hline
\end{tabular}

*Empiric dose changes should be done in conjunction with therapeutic drug monitoring.

Abbreviations: BOC, boceprevir; TVR, telaprevir; SMV, simeprevir; SFV, sofosbuvir; CYP3A4, cytochrome P450 3A4; mTOR, mammalian target of rapamycin; MMF, mycophenolate mofetil 
levels of hepatitis $C$ viremia. Notably, the majority of patients had not experienced ACR during treatment and yet evolved to CR. ${ }^{64} \mathrm{As}$ in ACR, the diagnosis of CR requires liver biopsy. The pathogenesis of $C R$ remains unclear, and most patients who had graft failure secondary to CR required $\mathrm{RT}^{64}$ It should be noted that IFN-related CR may be partly preventable by ensuring that the immunosuppressant dose is not reduced during antiviral therapy. ${ }^{66}$

Autoimmune hepatitis (AIH)-like hepatitis after LT has been reported in $\mathrm{HCV}$ patients, particularly with IFN-based therapy. ${ }^{19,64,67}$ The histological hallmarks can somewhat resemble classical $\mathrm{AIH}$, including plasma cell-predominant periportal infiltrates with interface hepatitis or so called plasma cell-rich hepatitis. Increased serum transaminase levels are seen during, or after HCV therapy, or in some cases, without a history of antiviral therapy. Autoantibodies are often absent or present with low titers. The majority of cases rapidly respond to increased immunosuppression with or without discontinuation of antiviral therapy. ${ }^{19,64,67}$ Adding everolimus may also be an option. ${ }^{68}$ Whether this AIH-like hepatitis is a variant of ACR or is de novo AIH is a matter of debate. ${ }^{67}$

\section{Immunosuppressive regimens}

The impact of immunosuppressive agents on HCV viremia, histologic recurrence, and treatment outcomes has been extensively debated. Immunosuppressive agents may facilitate HCV replication and enhance HCV disease progression. High-dose intravenous corticosteroid for the treatment of ACR has been accompanied by a transient increase in HCVRNA and an increased incidence of severe HCV recurrence. ${ }^{2,3}$ However, in a randomized controlled trial of $312 \mathrm{HCV}+\mathrm{LT}$ recipients with a steroid-free arm (induction by daclizumab), there were no differences in HCV recurrence and graft survival between steroid-free and steroid utilizing regimens. ${ }^{69}$ Therefore, there is no indication, specifically for $\mathrm{HCV}$, to avoid oral corticosteroids in the early postoperative period.

Treatment of steroid-resistant ACR with anti-CD 3 monoclonal antibody, OKT3, is a strong risk factor for both the time to development and the severity of recurrent $\mathrm{HCV}^{2,3,9}$ Based on limited data, other induction antibody therapies, such as anti-thymocyte globulins (ATG), anti-lymphocyte globulins, daclizumab, and basiliximab, have been noted to have little effect on recurrent $\mathrm{HCV}^{2,3,9}$

Some immunosuppressive agents have antiviral and antiinflammatory properties, which may in turn alleviate HCV disease progression. Cyclosporine A (CSA) has been shown to have antiviral effect against HCV by inhibiting interactions between cyclophilin B and NS5B-RNA-dependent-RNA polymerase. This effect has not been demonstrated with TAC. Whether this in vitro data can translate into the clinical arena remains controversial. In a randomized controlled trial of 95 $\mathrm{HCV}+\mathrm{LT}$ recipients comparing CSA-based and TAC-based regimens, CSA was associated with lower rates of severe $\mathrm{HCV}$ recurrence $(46 \%$ vs. $80 \%)$ and graft loss (6\% vs. $13 \%$, respectively) after a three year follow-up. ${ }^{70}$ However, a recent prospective controlled trial (253 HCV+ LT recipients) with seven year follow-up reported conflicting results. There was no significant difference in severity of HCV recurrence, SVR rates (in those 69 patients who received antiviral therapy), and graft and patient survival between CSA and TAC groups. ${ }^{71}$ Recent meta-analyses suggested no difference in HCV recurrence between TAC and CSA regimens, but TAC increased graft and patient survival in HCV transplanted patients. ${ }^{72}$ Interestingly, a synergistic role of CSA in combination with antiviral therapy has been suggested. Sugawara et al. reported on 21 living-donor LT patients with HCV recurrence that were treated with PEG-IFN/RBV while maintained on a TAC-based regimen. Among eight patients who had no virologic response after six months of treatment and were switched from TAC to CSA, five patients (63\%) became HCV-RNA negative within three months of conversion. ${ }^{73}$ Recently, a pilot study from Firpi et al. randomized 38 patients with $\mathrm{HCV}$ recurrence treated with TAC to either continue TAC or switch to CSA before initiation of PEG-IFN/ RBV. ${ }^{74}$ A modest HCV-RNA drop with a trend toward better virologic responses in the CSA group was observed; although statistical significance was not reached. ${ }^{74}$ Taken together, the impact of CSA on HCV recurrence or on antiviral therapy response appears to be neutral or beneficial. ${ }^{4}$ Therefore, the utilization of CSA in all HCV+ LT recipients must be deliberated with the caveat that TAC appears to be an overall better immunosuppressive agent. ${ }^{72,75}$ The strategy to switch from TAC to CSA before antiviral therapy needs to be further validated.

Data from in vitro studies suggest that mycophenolate mofetil (MMF) could have an antiviral effect against HCV through inhibition of inosine monophosphate dehydrogenase (IMPDH) and enhance the effect of CSA and IFN-based therapy. 3,76 However, neither an effect on HCV-RNA nor serum transaminases has been clearly demonstrated in clinical studies. ${ }^{3,76}$ An analysis from United Network of Organ Sharing/Scientific Registry of Transplant Recipients (UNOS/SRTR) database suggests that addition of MMF to TAC-based regimen is associated with improved long-term outcomes after LT in patients with and without HCV. ${ }^{77} \mathrm{~A}$ randomized, multicenter trial conducted in Japan $(\mathrm{N}=75)$ comparing TAC plus MMF to TAC plus steroids in HCV+ recipients of living donor $L T$ has reported similar outcomes (survival, ACR, recurrent $\mathrm{HCV}$ and $\mathrm{HCC}$ ) at five years in the two groups. ${ }^{78}$

mTOR inhibitors, such as sirolimus and everolimus, have anti-proliferative, anti-inflammatory, and possible antiviral effects, which may translate to a lower rate of HCV disease evolving to cirrhosis. ${ }^{79,80}$ A retrospective analysis of 141 $\mathrm{HCV}+\mathrm{LT}$ recipients demonstrated that a sirolimus-based regimen did not significantly delay the time to develop severe recurrence of $\mathrm{HCV}$ after $\mathrm{LT} .^{79}$ In contrast, in a prospective cohort of 67 patients (39 received sirolimus, 28 received calcineurin inhibitors), the sirolimus group had significantly lower HCV-RNA levels and increased survival. ${ }^{81}$ In addition, two independent retrospective studies ( $N=1274$ and 313) have demonstrated with sirolimus a reduction in the degree of fibrosis and the rate of progression in $\mathrm{HCV}+\mathrm{LT}$ recipients. ${ }^{82,83}$ However, an analysis of 26,414 patients $(12,589$ with $\mathrm{HCV}$ ) in the UNOS/SRTR database suggested a link between sirolimus use and risk of death and graft loss after LT in $\mathrm{HCV}$ patients that was not seen in patients without HCV. ${ }^{84}$ These conflicting data warrant further and well-designed longitudinal studies to delineate the impact of sirolimus on $\mathrm{HCV}$ recurrence.

\section{Donor and recipient genetic background}

Genetic variation in the IL28B gene, which encodes the antiviral cytokine IFN-ë3, is strongly associated with SVR in 
Bunchorntavakul C. et al.: Hepatitis C before and after liver transplantation

patients with chronic HCV infection treated with PEG-IFN/ RBV. A genome-wide association study of more than 1,600 patients infected with HCV genotype 1 found the rate of SVR following PEG-IFN/RBV treatment to be approximately $80 \%$, $40 \%$, and $25 \%$ in IL28B genotypes CC, CT, and $T$, respectively. ${ }^{85}$ Following LT, IL28B polymorphisms have been associated with histological recurrence and treatment response. ${ }^{8,10,46,47}$ Recipient CC genotype has been shown to be an independent predictor of delayed HCV recurrence at two and five years after LT and was associated with slower progression of fibrosis. ${ }^{8,10}$ Following HCV recurrence, treatment response has a stronger association with the CC genotype of the donor than the recipient. ${ }^{21,46,47}$ Although IL28B polymorphisms predict post-LT recurrence and clearance of HCV, these findings have not yet been demonstrated to improve graft or patient survival. Therefore, the use of $I L 28 B$ in donor selection, particularly in the context of live donor LT and in the management of HCV, warrants further study.

\section{Retransplantation (RT)}

Following HCV recurrence after primary $L T$, RT remains the only option for patients with decompensated cirrhosis. Regardless of HCV status, RT is associated with decreased patient and graft survival compared with primary LT. ${ }^{86}$ However, it is unclear whether HCV is an independent risk factor for survival or not. It is generally accepted that progression to cirrhosis is faster after RT than after primary LT, particularly in patients with severe hepatitis $C$ recurrence (cholestatic hepatitis and graft failure within the first year). ${ }^{86}$ UNOS data from 1994-2005 demonstrated that despite improved outcomes with RT overall, HCV patients continue to have worse patient and graft survival rates compared to non-HCV patients. ${ }^{87}$ Additional variables such as increased severity of illness pre-RT may account for decreased survival in this group following RT. As a result, the role of RT in HCV+ LT recipients remains controversial due to concerns of accelerated recurrence leading to rapid graft loss. A score specifically designed for to predict survival after RT for HCV has been proposed. ${ }^{88}$ This score includes variables from the first transplant (recipient age), second transplant (donor age, creatinine, INR, and serum albumin), and the interval between both transplants. The area under the ROC (receiver operating characteristic) curve was 0.643 at three years, and survivals were $71 \%, 56 \%$, and $37 \%$ for scores $<30,30$ to 40 , and $>40$, respectively. ${ }^{88}$ In an era of organ shortage, the use of well-validated prognostic scores is recommended to limit RT to patients with reasonable survival probability. ${ }^{86}$

\section{Conclusions}

Management of hepatitis C in LT population presents unique challenges. Suboptimal graft survival in $\mathrm{HCV}+\mathrm{LT}$ recipients is attributable to universal HCV recurrence following LT. Eradication of HCV before LT is ideal to prevent HCV recurrence, but is often limited by adverse events, particularly in patients with advanced cirrhosis. Antiviral therapy in LT candidates needs careful monitoring and DAA-based triple therapy is generally not recommended, except by those who have experience with such therapy. Prophylaxis with HCV antibodies is ineffective. Early antiviral therapy after LT has been investigated, but no clear benefit has been demonstrated. Protocol liver biopsy is generally recommended in
$\mathrm{HCV}+\mathrm{LT}$ recipients, and antiviral therapy may be considered in those with severe/progressive HCV recurrence. SVR can be achieved in approximately $30 \%$ of LT recipients with PEG-IFN/ RBV. However, adverse effects are common and about onequarter of patients discontinue treatment prematurely. Survival benefit is evident in those patients who achieve SVR. Favorable patient characteristics for response to therapy include non-1 genotype, previously untreated, low baseline HCV-RNA, and donor IL28B genotype CC. DAA-based triple therapy is associated with higher rates of SVR, but with similar or slightly higher rates of side effects, and immunosuppressive regimens need to be adjusted and closely monitored for the levels during the treatment period. Notably, the safety and efficacy of HCV treatment are very likely to improve with newer generation DAA. The impact of immunosuppressive strategy on the natural history $\mathrm{HCV}$ recurrence has not been well elucidated. Based upon available evidence, CSA, MMF, and sirolimus appear to have a neutral or small beneficial impact on HCV recurrence. Donor IL28B polymorphisms appear to impact the course and treatment outcomes in recurrent HCV. Retransplantation should be considered for patients with reasonable survival probability.

\section{Conflict of interest}

None

\section{Author contributions}

Literatures reviewing, manuscript drafting, figures and tables creating $(\mathrm{CB})$, conceptualization and critically revision of the manuscript (KRR).

\section{References}

[1] Davis GL, Alter MJ, El-Serag H, Poynard T, Jennings LW. Aging of hepatitis C virus (HCV)-infected persons in the United States: a multiple cohort model of HCV prevalence and disease progression. Gastroenterology 2010;138:513521. doi: 10.1053/j.gastro.2009.09.067.

[2] Gane EJ. The natural history of recurrent hepatitis $C$ and what influences this. Liver Transpl 2008;14 (Suppl 2):36-44. doi: 10.1002/It.21646.

[3] Watt K, Veldt B, Charlton M. A practical guide to the management of HCV infection following liver transplantation. Am J Transplant 2009;9:1707-1713.

[4] Bunchorntavakul C, Bonnel AR, Reddy KR. Management of hepatitis before and after liver transplantation. In: Arroyo $V$, editor. Management of Hepatitis C: International Hepatology Updates Series. Barcelona: Permanyer Publications; 2011.

[5] Reddy KR, Bunchorntavakul C. Managing hepatitis C: before and after liver transplantation. Indian J Transplant 2011;5:72-76.

[6] Alberti A, Vario A, Ferrari A, Pistis R. Review article: chronic hepatitis Cnatural history and cofactors. Aliment Pharmacol Ther 2005;22 (Suppl 2): 74-78. doi: 10.1111/j.1365-2036.2005.02602.x.

[7] Forman LM, Lewis JD, Berlin JA, Feldman HI, Lucey MR. The association between hepatitis $C$ infection and survival after orthotopic liver transplantation. Gastroenterology 2002;122:889-896. doi: 10.1053/gast.2002.32418.

[8] Charlton MR, Thompson A, Veldt BJ, Watt K, Tillmann H, Poterucha JJ, et al. Interleukin-28B polymorphisms are associated with histological recurrence and treatment response following liver transplantation in patients with hepatitis C virus infection. Hepatology 2011;53:317-324. doi: 10.1002/ hep.24074.

[9] Roche B, Samuel D. Risk factors for hepatitis C recurrence after liver transplantation. J Viral Hepat 2007;14 (Suppl 1):89-96. doi: 10.1111/ j.1365-2893.2007.00920.x.

[10] Ackefors M, Nystrom J, Wernerson A, Gjertsen H, Sonnerborg A, Weiland O. Evolution of fibrosis during $\mathrm{HCV}$ recurrence after liver transplantationinfluence of IL-28B SNP and response to peg-IFN and ribavirin treatment. J Viral Hepat 2013;20:770-778. 
[11] Garcia-Retortillo M, Forns X, Feliu A, Moitinho E, Costa J, Navasa M, et al. Hepatitis $C$ virus kinetics during and immediately after liver transplantation. Hepatology 2002;35:680-687. doi: 10.1053/jhep.2002.31773.

[12] Narang TK, Ahrens W, Russo MW. Post-liver transplant cholestatic hepatitis C: a systematic review of clinical and pathological findings and application of consensus criteria. Liver Transpl 2010;16:1228-1235. doi: 10.1002/ It. 22175 .

[13] Neff GW, Shire N, Ruiz P, O'Brien C, Garcia M, Dela Garza J, et al. The importance of clinical parameters when differentiating cholestatic hepatitis $C$ virus from allograft rejection. Transplant Proc 2005;37:4397-4402. doi: 10.1016/j.transproceed.2005.10.012.

[14] Bellido-Munoz F, Giraldez-Gallego A, Roca-Oporto C, Garcia-Cayuela T, Pascasio-Acevedo JM, Sousa-Martin JM. Monitoring the natural evolution and response to treatment of post liver transplant recurrent hepatitis $C$ using transient elastography: preliminary results. Transplant Proc 2012;44:20822086. doi: 10.1016/j.transproceed.2012.07.090.

[15] J S Cross T, Jothimani D, Heneghan MA, Harrison PM. Non-invasive assessment of fibrosis in liver grafts due to hepatitis $C$ virus recurrence. Clin Transplant 2011:25:345-351. doi: 10.1111/j.1399-0012.2011.01396.x.

[16] Cholongitas E, Tsochatzis E, Goulis J, Burroughs AK. Noninvasive tests for evaluation of fibrosis in $\mathrm{HCV}$ recurrence after liver transplantation: a systematic review. Transpl Int 2010;23:861-870. doi: 10.1111/j.14322277.2010.01142.x.

[17] Rigamonti C, Donato MF, Colombo M. Transient elastography in the early prediction of progressive recurrent hepatitis $\mathrm{C}$ following liver transplantation. Hepatology 2010;52:800-801. doi: 10.1002/hep.23607.

[18] Crespo G, Lens S, Gambato M, Carrion JA, Marino Z, Londono MC, et al. Liver Stiffness 1 Year After Transplantation Predicts Clinical Outcomes in Patients With Recurrent Hepatitis C. Am J Transplant 2014;14:375-383. doi: 10.1111/ajt.12594.

[19] Terrault NA. Hepatitis C therapy before and after liver transplantation. Liver Transpl 2008;14 (Suppl 2):S58-66. doi: 10.1002/It.21624.

[20] Roche B, Samuel D. Hepatitis C virus treatment pre- and post-liver transplantation. Liver Int 2012;32 (Suppl 1):120-128. doi: 10.1111/ j.1478-3231.2011.02714.x.

[21] Coto-Llerena M, Perez-Del-Pulgar S, Crespo G, Carrion JA, Martinez SM, Sanchez-Tapias JM, et al. Donor and Recipient IL28B Polymorphisms in HCVInfected Patients Undergoing Antiviral Therapy before and after Liver Transplantation. Am J Transplant 2011;11:1051-1057.

[22] Carrion JA, Martinez-Bauer E, Crespo G, Ramirez S, Perez-del-Pulgar S, Garcia-Valdecasas JC, et al. Antiviral therapy increases the risk of bacterial infections in $\mathrm{HCV}$-infected cirrhotic patients awaiting liver transplantation: A retrospective study. J Hepatol 2009;50:719-728. doi: 10.1016/ j.jhep.2008.11.015.

[23] Osinusi A, Meissner EG, Lee Y], Bon D, Heytens L, Nelson A, et al. Sofosbuvir and ribavirin for hepatitis $C$ genotype 1 in patients with unfavorable treatment characteristics: a randomized clinical trial. JAMA 2013;310:804811. doi: 10.1001/jama.2013.109309.

[24] Jacobson IM, McHutchison JG, Dusheiko G, Di Bisceglie AM, Reddy KR, Bzowej NH, et al. Telaprevir for previously untreated chronic hepatitis $\mathrm{C}$ virus infection. N Engl J Med 2011;364:2405-2416.

[25] Zeuzem S, Andreone P, Pol S, Lawitz E, Diago M, Roberts S, et al. Telaprevir for retreatment of HCV infection. N Engl J Med 2011;364:2417-2428.

[26] Bacon BR, Gordon SC, Lawitz E, Marcellin P, Vierling JM, Zeuzem S, et al. Boceprevir for previously treated chronic HCV genotype 1 infection. N Engl J Med 2011;364:1207-1217.

[27] Poordad F, McCone J, Jr., Bacon BR, Bruno S, Manns MP, Sulkowski MS, et al. Boceprevir for untreated chronic HCV genotype 1 infection. N Engl J Med 2011;364:1195-1206

[28] Fried MW, Buti M, Dore GJ, Flisiak R, Ferenci P, Jacobson I, et al. Once-daily simeprevir (TMC435) with pegylated interferon and ribavirin in treatmentnaive genotype 1 hepatitis C: The randomized PILLAR study. Hepatology 2013;58:1918-1929. doi: 10.1002/hep.26641.

[29] Hezode C, Fontaine H, Dorival C, Larrey D, Zoulim F, Canva V, et al. Triple therapy in treatment-experienced patients with HCV-cirrhosis in a multicentre cohort of the French Early Access Programme (ANRS CO20-CUPIC) NCT01514890. J Hepatol 2013;59:434-441. doi: 10.1016/j.jhep.2013. 04.035.

[30] Gane EJ, Stedman CA, Hyland RH, Ding X, Svarovskaia E, Subramanian GM, et al. Efficacy of Nucleotide Polymerase Inhibitor Sofosbuvir plus the NS5A Inhibitor Ledipasvir or the NS5B Non-nucleoside Inhibitor GS-9669 Against HCV Genotype 1 Infection. Gastroenterology 2014;146:736-743. doi: 10.1053/j.gastro.2013.11.007.

[31] Kwo PY, Tector AJ. Oral direct-acting antiviral therapy to prevent reinfection of the liver graft after liver transplantation for hepatitis $C$ virus-related cirrhosis. Liver Transpl 2013;19:780-781. doi: 10.1002/lt.23662.

[32] Curry MP, Forns X, Chung RT, Terrault N, Brown RS, Fenkel JM, et al. Pretransplant sofosbuvir and ribavirin to prevent recurrence of $\mathrm{HCV}$ infection after liver transplantation. Hepatology 2013;58:314A.
[33] Wiesner RH, Sorrell M, Villamil F. Report of the first International Liver Transplantation Society expert panel consensus conference on liver transplantation and hepatitis C. Liver Transpl 2003;9:S1-9. doi: 10.1053/ jlts.2003.50268

[34] Davis GL, Nelson DR, Terrault N, Pruett TL, Schiano TD, Fletcher CV, et al. A randomized, open-label study to evaluate the safety and pharmacokinetics of human hepatitis $\mathrm{C}$ immune globulin (Civacir) in liver transplant recipients. Liver Transpl 2005;11:941-949. doi: 10.1002/lt.20405.

[35] Schiano TD, Charlton M, Younossi Z, Galun E, Pruett T, Tur-Kaspa R, et al. Monoclonal antibody HCV-AbXTL68 in patients undergoing liver transplantation for HCV: results of a phase 2 randomized study. Liver Transpl 2006;12: 1381-1389. doi: 10.1002/It.20876.

[36] Neumann UP, Biermer M, Eurich D, Neuhaus P, Berg T. Successful prevention of hepatitis $\mathrm{C}$ virus (HCV) liver graft reinfection by silibinin mono-therapy. J Hepatol 2010;52:951-952. doi: 10.1016/j.jhep.2010.02.002.

[37] Gurusamy KS, Tsochatzis E, Toon CD, Davidson BR, Burroughs AK. Antiviral prophylaxis for the prevention of chronic hepatitis $C$ virus in patients undergoing liver transplantation. Cochrane Database Syst Rev 2013;12: CD006573.

[38] Castells L, Vargas V, Allende H, Bilbao I, Luis Lazaro J, Margarit C, et al. Combined treatment with pegylated interferon (alpha-2b) and ribavirin in the acute phase of hepatitis $C$ virus recurrence after liver transplantation. J Hepatol 2005;43:53-59. doi: 10.1016/j.jhep.2005.02.015.

[39] Zimmermann T, Bocher WO, Biesterfeld S, Zimmermann A, Kanzler S, GreifHiger $\mathrm{G}$, et al. Efficacy of an escalating dose regimen of pegylated interferon alpha-2a plus ribavirin in the early phase of HCV reinfection after liver transplantation. Transpl Int 2007;20:583-590. doi: 10.1111/j.14322277.2007.00481.x

[40] Bzowej N, Nelson DR, Terrault NA, Everson GT, Teng LL, Prabhakar A, et al. PHOENIX: A randomized controlled trial of peginterferon alfa-2a plus ribavirin as a prophylactic treatment after liver transplantation for hepatitis C virus. Liver Transpl 2011;17:528-538. doi: 10.1002/It.22271.

[41] Veldt BJ, Poterucha JJ, Watt KD, Wiesner RH, Hay JE, Kremers WK, et al. Impact of pegylated interferon and ribavirin treatment on graft survival in liver transplant patients with recurrent hepatitis C infection. Am J Transplant 2008; 8:2426-2433.

[42] Berenguer M, Palau A, Aguilera V, Rayon JM, Juan FS, Prieto M. Clinical benefits of antiviral therapy in patients with recurrent hepatitis $C$ following liver transplantation. Am J Transplant 2008;8:679-687.

[43] Berenguer M. Systematic review of the treatment of established recurrent hepatitis $C$ with pegylated interferon in combination with ribavirin. J Hepatol 2008;49:274-287. doi: 10.1016/j.jhep.2008.05.002.

[44] Wang CS, Ko HH, Yoshida EM, Marra CA, Richardson K. Interferon-based combination anti-viral therapy for hepatitis $C$ virus after liver transplantation: a review and quantitative analysis. Am J Transplant 2006;6:15861599.

[45] Xirouchakis E, Triantos C, Manousou P, Sigalas A, Calvaruso V, Corbani A, et al. Pegylated-interferon and ribavirin in liver transplant candidates and recipients with HCV cirrhosis: systematic review and meta-analysis of prospective controlled studies. J Viral Hepat 2008;15:699-709. doi: 10.1111/j.1365-2893.2008.01019.x.

[46] Lange CM, Moradpour D, Doehring A, Lehr HA, Mullhaupt B, Bibert S, et al. Impact of donor and recipient IL28B rs12979860 genotypes on hepatitis C virus liver graft reinfection. J Hepatol 2011;55:322-327. doi: 10.1016/ j.jhep.2010.10.037.

[47] Firpi RJ, Dong H, Clark VC, Soldevila-Pico C, Morelli G, Cabrera R, et al. CC genotype donors for the interleukin-28B single nucleotide polymorphism are associated with better outcomes in hepatitis $\mathrm{C}$ after liver transplant. Liver Int 2013;33:72-78. doi: 10.1111/liv.12013.

[48] Hanouneh IA, Miller C, Aucejo F, Lopez R, Quinn MK, Zein NN. Recurrent hepatitis $C$ after liver transplantation: on-treatment prediction of response to peginterferon/ribavirin therapy. Liver Transpl 2008;14:53-58. doi: 10.1002/ It.21312.

[49] Tischer S, Fontana RJ. Drug-drug interactions with oral anti-HCV agents and Idiosyncratic Hepatotoxicity in the Liver Transplant setting. J Hepatol 2014; 60:872-884.

[50] Frassetto LA, Browne M, Cheng A, Wolfe AR, Roland ME, Stock PG, et al. Immunosuppressant pharmacokinetics and dosing modifications in HIV-1 infected liver and kidney transplant recipients. Am J Transplant 2007;7: 2816-2820.

[51] Garg V, van Heeswijk R, Lee JE, Nadkarni KA, Luo X. The effect of telaprevir on the pharmacokinetics of cyclosporine and tacrolimus. Hepatology 2011 54:20-27. doi: 10.1002/hep.24443.

[52] Charlton M, Dick T. Victory and defeat at Heraclea - Treating hepatitis C infection following liver transplantation with telaprevir and boceprevir. J Hepatol 2014;60:6-8. doi: 10.1016/j.jhep.2013.10.006.

[53] Coilly A, Furlan V, Roche B, Barau C, Noel C, Bonhomme-Faivre L, et al. Practical management of boceprevir and immunosuppressive therapy in liver transplant recipients with hepatitis $C$ virus recurrence. Antimicrob Agents Chemother 2012;56:5728-5734. doi: 10.1128/AAC.01151-12. 
[54] Coilly A, Roche B, Dumortier ], Leroy V, Botta-Fridlund D, Radenne S, et al. Safety and efficacy of protease inhibitors to treat hepatitis $C$ after liver transplantation: A multicenter experience. J Hepatol 2014;60:78-86. doi: 10.1016/j.jhep.2013.08.018.

[55] Werner CR, Egetemeyr DP, Lauer UM, Nadalin S, Konigsrainer A, Malek NP, et al. Telaprevir-based triple therapy in liver transplant patients with hepatitis $C$ virus: a 12-week pilot study providing safety and efficacy data. Liver Transpl 2012;18:1464-1470. doi: 10.1002/lt.23542.

[56] Hulskotte E, Gupta S, Xuan F, van Zutven M, O'Mara E, Feng HP, et al. Pharmacokinetic interaction between the hepatitis $C$ virus protease inhibitor boceprevir and cyclosporine and tacrolimus in healthy volunteers. Hepatology 2012;56:1622-1630. doi: 10.1002/hep.25831.

[57] Reddy KR, Everson GT. Treatment of chronic hepatitis C with protease inhibitor-based therapy after liver transplantation. Hepatology 2013;58: 1181-1184. doi: 10.1002/hep.26612.

[58] Werner CR, Egetemeyr DP, Lauer UM, Nadalin S, Konigsrainer A, Malek NP, et al. Feasibility of Telaprevir-Based Triple Therapy in Liver Transplant Patients with Hepatitis C Virus: SVR 24 Results. PLoS One 2013;8:e80528. doi: $10.1371 /$ journal.pone.0080528.

[59] Massoud O, Wiesner RH. The use of sirolimus should be restricted in liver transplantation. J Hepatol 2012;56:288-290. doi: 10.1016/j.jhep.2011. 06.012.

[60] Charlton M, Gane EJ, Manns MP, Brown RS, Curry MP, Kwo PY, et al. Sofosbuvir and ribavirin for the treatment of established recurrent hepatitis $C$ infection after liver transplantation: preliminary results of a prospective, multicenter study. Hepatology, 2013; 58(Suppl): 1378A.

[61] Fontana RJ, Hughes EA, Appelman H, Hindes R, Dimitrova D, Bifano M. Case report of successful peginterferon, ribavirin, and daclatasvir therapy for recurrent cholestatic hepatitis C after liver retransplantation. Liver Transpl 2012;18:1053-1059. doi: 10.1002/It.23482.

[62] Fontana RJ, Hughes EA, Bifano M, Appelman H, Dimitrova D, Hindes R, et al. Sofosbuvir and daclatasvir combination therapy in a liver transplant recipient with severe recurrent cholestatic hepatitis C. Am J Transplant 2013;13: 1601-1605. doi: 10.1111/ajt.12209.

[63] Jacobson IM, Cacoub P, Dal Maso L, Harrison SA, Younossi ZM. Manifestations of chronic hepatitis $C$ virus infection beyond the liver. Clin Gastroenterol Hepatol 2010;8:1017-1029. doi: 10.1016/j.cgh.2010.08.026.

[64] Selzner N, Guindi M, Renner EL, Berenguer M. Immune-mediated complications of the graft in interferon-treated hepatitis $C$ positive liver transplant recipients. J Hepatol 2011;55:207-217. doi: 10.1016/j.jhep.2010.11.012.

[65] Charco R, Vargas V, Allende H, Edo A, Balsells J, Murio E, et al. Is hepatitis C virus recurrence a risk factor for chronic liver allograft rejection? Transpl Int 1996:9 (Suppl 1):S195-197. doi: 10.1111/j.1432-2277.1996.tb01606.x.

[66] Ueda Y, Kaido T, Ito T, Ogawa K, Yoshizawa A, Fujimoto Y, et al. Chronic Rejection Associated with Antiviral Therapy for Recurrent Hepatitis C after Living-Donor Liver Transplantation. Transplantation 2014;97:344-350. doi: 10.1097/01.TP.0000435702.61642.0a.

[67] Fiel MI, Agarwal K, Stanca C, Elhajj N, Kontorinis N, Thung SN, et al. Posttransplant plasma cell hepatitis (de novo autoimmune hepatitis) is a variant of rejection and may lead to a negative outcome in patients with hepatitis C virus. Liver Transpl 2008;14:861-871. doi: 10.1002/lt.21447.

[68] Casanovas T, Argudo A, Pena-Cala MC. Effectiveness and safety of everolimus in the treatment of autoimmune hepatitis related to anti-hepatitis $C$ virus therapy after liver transplant: three case reports. Transplant Proc 2011; 43:2233-2236. doi: 10.1016/j.transproceed.2011.05.028.

[69] Klintmalm GB, Washburn WK, Rudich SM, Heffron TG, Teperman LW, Fasola C, et al. Corticosteroid-free immunosuppression with daclizumab in $\mathrm{HCV}(+)$ liver transplant recipients: 1 -year interim results of the HCV-3 study. Liver Transpl 2007:13:1521-1531. doi: 10.1002/It.21182.

[70] Villamil F, Levy G, Grazi GL, Mies S, Samuel D, Sanjuan F, et al. Long-term outcomes in liver transplant patients with hepatic $C$ infection receiving tacrolimus or cyclosporine. Transplant Proc 2006;38:2964-2967. doi: 10.1016/j.transproceed.2006.08.131.

[71] Berenguer M, Aguilera V, San Juan F, Benlloch S, Rubin A, Lopez-Andujar R, et al. Effect of calcineurin inhibitors in the outcome of liver transplantation in hepatitis C virus-positive recipients. Transplantation 2010;90:1204-1209. doi: 10.1097/TP.0b013e3181fa93fa.

[72] Samonakis DN, Germani G, Burroughs AK. Immunosuppression and HCV recurrence after liver transplantation. J Hepatol 2012;56:973-983. doi: 10.1016/j.jhep.2011.06.031.

[73] Sugawara Y, Kaneko J, Makuuchi M. Cyclosporin a for treatment of hepatitis C virus after liver transplantation. Transplantation 2006;82:579-580. doi: 10.1097/01.tp.0000229397.81425.51.

[74] Firpi RJ, Soldevila-Pico C, Morelli GG, Cabrera R, Levy C, Clark VC, et al. The use of cyclosporine for recurrent hepatitis C after liver transplant: a randomized pilot study. Dig Dis Sci 2010;55:196-203. doi: 10.1007/ s10620-009-0981-3.

[75] McAlister VC, Haddad E, Renouf E, Malthaner RA, Kjaer MS, Gluud LL. Cyclosporin versus tacrolimus as primary immunosuppressant after liver transplantation: a meta-analysis. Am J Transplant 2006;6:1578-1585.

[76] Henry SD, Metselaar HJ, Lonsdale RC, Kok A, Haagmans BL, Tilanus HW, et al. Mycophenolic acid inhibits hepatitis $C$ virus replication and acts in synergy with cyclosporin A and interferon-alpha. Gastroenterology 2006; 131:1452-1462. doi: 10.1053/j.gastro.2006.08.027.

[77] Wiesner RH, Shorr JS, Steffen BJ, Chu AH, Gordon RD, Lake JR. Mycophenolate mofetil combination therapy improves long-term outcomes after liver transplantation in patients with and without hepatitis C. Liver Transpl 2005;11:750-759. doi: 10.1002/lt.20453.

[78] Takada $\mathrm{Y}$, Kaido $\mathrm{T}$, Asonuma $\mathrm{K}$, Sakurai $\mathrm{H}$, Kubo $\mathrm{S}$, Kiuchi $\mathrm{T}$, et al. Randomized, multicenter trial comparing tacrolimus plus mycophenolate mofetil to tacrolimus plus steroids in hepatitis $C$ virus-positive recipients of living donor liver transplantation. Liver Transpl 2013;19:896-906. doi: $10.1002 /$ It.23679.

[79] Asthana S, Toso C, Meeberg G, Bigam DL, Mason A, Shapiro J, et al. The impact of sirolimus on hepatitis $C$ recurrence after liver transplantation. Can J Gastroenterol 2011;25:28-34.

[80] Chan AJ, Lake JR. Immunosuppression in HCV-positive liver-transplant recipients. Curr Opin Organ Transplant 2012;17:648-654. doi: 10.1097/ MOT.0b013e32835a2b5a.

[81] Wagner D, Kniepeiss D, Schaffellner S, Jakoby E, Mueller H, FahrleitnerPammer A, et al. Sirolimus has a potential to influent viral recurrence in HCV positive liver transplant candidates. Int Immunopharmacol 2010;10:990993. doi: 10.1016/j.intimp.2010.05.006.

[82] Kelly MA, Kaplan M, Nydam T, Wachs M, Bak T, Kam I, et al. Sirolimus reduces the risk of significant hepatic fibrosis after liver transplantation for hepatitis $C$ virus: a single-center experience. Transplant Proc 2013;45:3325-3328. doi: 10.1016/j.transproceed.2013.04.011.

[83] McKenna GJ, Trotter JF, Klintmalm E, Onaca N, Ruiz R, Jennings LW, et al. Limiting hepatitis $C$ virus progression in liver transplant recipients using sirolimus-based immunosuppression. Am J Transplant 2011;11:2379-2387.

[84] Watt KD, Dierkhising R, Heimbach JK, Charlton MR. Impact of sirolimus and tacrolimus on mortality and graft loss in liver transplant recipients with or without hepatitis C virus: an analysis of the Scientific Registry of Transplant Recipients Database. Liver Transpl 2012;18:1029-1036. doi: 10.1002/ It. 23479 .

[85] Ge D, Fellay J, Thompson AJ, Simon JS, Shianna KV, Urban TJ, et al. Genetic variation in IL28B predicts hepatitis C treatment-induced viral clearance. Nature 2009;461:399-401. doi: 10.1038/nature08309.

[86] Carrion JA, Navasa M, Forns X. Retransplantation in patients with hepatitis $C$ recurrence after liver transplantation. J Hepatol 2010;53:962-970. doi: 10.1016/j.jhep.2010.06.006.

[87] Ghabril M, Dickson R, Wiesner R. Improving outcomes of liver retransplantation: an analysis of trends and the impact of Hepatitis $\mathrm{C}$ infection. Am J Transplant 2008;8:404-411.

[88] Andres A, Gerstel E, Combescure C, Asthana S, Merani S, Majno P, et al. A score predicting survival after liver retransplantation for hepatitis C virus cirrhosis. Transplantation 2012;93:717-722. doi: 10.1097/TP. ob013e318246f8b3. 